\title{
Temporal variability in birth prevalence of cardiovascular malformations
}

\author{
C Wren, S Richmond, L Donaldson
}

\begin{abstract}
Objective-To investigate changes over time in the prevalence at live birth of cardiovascular malformations and to compare "anatomical" and "physiological" diagnostic hierarchies within a population.

Design-Retrospective and prospective ascertainment of all congenital cardiovascular malformations diagnosed in infancy.

Setting-The resident population of one health region.

Patients-All infants live born from 1985 to 1997 with cardiovascular malformations confirmed by echocardiography, cardiac catheterisation, surgery or autopsy.

Main outcome measures-Year to year variation in prevalence of individual malformations and of "complex", "significant", and "minor" groups.

Results-2671 babies with cardiovascular malformations were confirmed in a denominator population of 477960 live births (5.6 per 1000). There was no change over 13 years in the birth prevalence of "complex" or "significant" defects, but a highly significant increase in "minor" defects $(\mathrm{p}<0.0001)$, mainly small ventricular septal defects. Termination of pregnancy increased from no cases in 1985 to 16 in 1997 with no demonstrable effect on live born babies with heart defects. A one dimensional "anatomical" diagnostic hierarchy led to under ascertainment of pulmonary atresia by $27 \%$, coarctation of the aorta by $39 \%$, and interruption of the aorta by $100 \%$. Conclusions-The apparent increase in live born cardiovascular malformations results mainly from improved diagnosis of minor defects. There has been no change over time in birth prevalence of more serious defects. Spontaneous year to year variation in numbers will make it difficult to ascribe any short term changes to any particular intervention. A two dimensional diagnostic hierarchy is offered as a standard.

(Heart 2000;83:414-419)
\end{abstract}

Keywords: congenital heart defects; epidemiology; infancy; temporal variability

Department of

Paediatric Cardiology, Freeman Hospital, Newcastle upon Tyne NE7 7DN, UK C Wren

Neonatal Unit, Sunderland Royal Hospital, Sunderland, UK

S Richmond

Department of Epidemiology and

Public Health, University of Newcastle upon Tyne, UK

L Donaldson

Correspondence to: DrWren

email: Christopher.Wren@ th.nuth.northy.nhs.uk

Accepted 6 January 2000
Cardiovascular malformations account for about $10 \%$ of all infant deaths and nearly half of all deaths from malformation. ${ }^{1}$ As a group they are the most common type of congenital malformation. $^{2}$ The cause of an increasing number of cardiovascular malformations is known to be genetic and a few are environmental in origin, but for the majority the cause is unknown. The descriptive epidemiology of cardiovascular malformations has generated much interest over the last 30-40 years but has not so far provided major clues to aetiology. There have been many descriptions of disease frequency but comparison between them is hampered by the lack of a common methodology. Early studies are limited by their inclusion of many unconfirmed clinical diagnoses (before ultrasound was widely available) ${ }^{3}$ and some more recent studies, which are institution based, are limited by their inability to define the population from which their patients were derived. ${ }^{4}$ Comparisons between studies are also made difficult by uncertainties over ascertainment and because of the different diagnostic categories and diagnostic hierarchies employed. ${ }^{5}$

The pattern of cardiovascular malformation is likely to be changing with time. Recognition and description of this has important implications for the future provision of services but may also give clues to the cause. Increasing antenatal recognition of congenital heart dis- ease and termination of affected pregnancies might be expected to reduce the prevalence at live birth of the more severe abnormalities. ${ }^{6}$ Changes over time may also reflect the random effect of small numbers ${ }^{5}$ or the increasing ascertainment of minor malformations with better non-invasive technology. ${ }^{78}$ The recognised increased risk to offspring of survivors of congenital heart disease might be expected, all other things being equal, to lead to a significant increase in the birth prevalence in the population over several generations. ${ }^{9}$

Our study aimed to: (1) define the birth prevalence of cardiovascular malformations in a well defined population in the era of readily accessible non-invasive imaging; (2) propose an acceptable diagnostic hierarchy to enable comparison with previous and future reports; and (3) to examine temporal variability in the birth prevalence of cardiovascular malformations.

\section{Methods}

POPULATION

The former Northern Health Region comprises the counties of Cumbria, Northumberland, Tyne and Wear, Durham, and Cleveland, and has a population of just over three million people. Babies with suspected heart disease from the health district of South Cumbria are referred elsewhere for geographical reasons. All babies with suspected heart disease from the 
other 15 of 16 health districts are referred to a single paediatric cardiology centre. ${ }^{10}$

DATA SOURCES

All cases of live born cardiovascular malformation diagnosed in the first 12 months of life were identified from the diagnostic database in the regional paediatric cardiology unit in the Freeman Hospital, Newcastle upon Tyne, and were cross checked with the northern congenital abnormality survey. ${ }^{11}$ The paediatric cardiology database was established in 1990 with prospective registration of all congenital heart defects since then. Ascertainment of cases born in 1985 to 1989 was retrospective from ward admission lists, hospital diagnostic coding, and the northern regional perinatal, late neonatal, and infant mortality survey, and is thought to be complete for all complex and significant malformations (see below). There is likely to be some under ascertainment of minor malformations in the early part of the study. The perinatal, late neonatal, and infant mortality survey also provided information on all terminations of pregnancy where a heart defect had been recognised antenatally and all cardiovascular malformations in live born babies where death occurred before diagnosis had been made. ${ }^{12}$ The Office of National Statistics provided data on the regional birth rate.

CASE DEFINITION

In this study, as in most previous studies, cardiovascular malformations were defined as by Mitchell and colleagues ${ }^{13}$ - that is, "a gross structural abnormality of the heart or intrathoracic great vessels that is actually or potentially of functional importance". To enable comparison with previous studies, cases of isolated cardiac arrhythmia, cardiomyopathy, acquired heart disease, isolated bicuspid aortic valve, mitral valve prolapse without regurgitation, isolated dextrocardia, cardiac tumours, patent ductus arteriosus associated with prematurity (that is, ductus requiring surgical ligation within six weeks of the due date of delivery), atrial septal defect undergoing spontaneous closure in infancy, and mild physiological pulmonary artery branch stenosis were excluded. Ascertainment was limited to malformations diagnosed by the age of 12 months. While most significant heart disease has presented by this time, relatively few cases of patent ductus and atrial septal defect are diagnosed by 12 months of age and even fewer have undergone treatment by this age. ${ }^{10}$ Because of this, data on isolated atrial septal defect and isolated patent ductus arteriosus diagnosed in infancy are presented separately.

\section{DIAGNOSTIC HIERARCHY}

Analysis of babies with multiple cardiovascular malformations is a difficult problem and all previous reports have allocated all cases a single diagnosis based on the malformation judged most important. There has been no consensus on an acceptable diagnostic hierarchy. Many previous studies have adopted either the classification proposed in the New England regional infant cardiac programme which defines a hierarchy based mainly on anatomical severity ${ }^{14}$ or that in the Baltimore-Washington infant study in which priority is given to "the malformation components with the earliest embryonic disturbance". ${ }^{15}$ In practice these two approaches using an "anatomical" hierarchy are broadly similar. Reports which are institution based and which cannot define the denominator population usually adopt a "physiological" hierarchy, taking as most

Table 1 Prevalence of individual cardiovascular malformations, including "anatomical” and "physiological" hierarchies

\begin{tabular}{|c|c|c|c|c|c|c|c|c|}
\hline & $P A$ & $I A A$ & $\operatorname{Co} A$ & TAPVC & ToF & All others & Total & $\begin{array}{l}\text { Rate/1000 live } \\
\text { births }\end{array}$ \\
\hline $\mathrm{HLH}$ & & & & & & 69 & 69 & 0.14 \\
\hline Mitral atresia & 2 & & 2 & 1 & & 8 & 13 & 0.03 \\
\hline Tricuspid atresia & 4 & & 2 & & & 19 & 25 & 0.05 \\
\hline DIV & 5 & 2 & 2 & & & 24 & 33 & 0.07 \\
\hline PA/IVS & & & & & & 23 & 23 & 0.05 \\
\hline $\mathrm{PA} / \mathrm{VSD}$ & & & & 1 & & 50 & 51 & 0.11 \\
\hline Truncus & & 6 & 1 & & & 37 & 44 & 0.09 \\
\hline CTGA & 6 & & & & & 13 & 19 & 0.04 \\
\hline CAVSD & 11 & & 9 & 2 & 7 & 102 & 131 & 0.27 \\
\hline TGA & & 4 & 2 & & & 139 & 145 & 0.30 \\
\hline ToF & & & & & & 146 & 146 & 0.31 \\
\hline PAVSD & & & 2 & & & 36 & 38 & 0.08 \\
\hline TAPVC & & & 1 & & & 44 & 45 & 0.09 \\
\hline VSD op/or death & & 20 & 37 & & & 184 & 241 & 0.50 \\
\hline AS op/or death & & & 6 & & & 40 & 46 & 0.10 \\
\hline PS op/or death & & & 1 & & & 52 & 53 & 0.11 \\
\hline $\mathrm{CoA}$ & & & & & & 116 & 116 & 0.24 \\
\hline ASD & & & 2 & & & 132 & 134 & 0.28 \\
\hline PDA & & & & & & 109 & 109 & 0.23 \\
\hline VSD & & & & & & 899 & 899 & 1.88 \\
\hline AS & & & & & & 47 & 47 & 0.10 \\
\hline PS & & & & & & 159 & 159 & 0.33 \\
\hline Miscellaneous & & 4 & 7 & & & 74 & 85 & 0.18 \\
\hline Total & 28 & 36 & 74 & 4 & 7 & 2522 & 2671 & 5.59 \\
\hline
\end{tabular}

PA, pulmonary atresia; IAA, interruption of the aortic arch; CoA, coarctation of the aortic arch; ToF, tetralogy of Fallot; HLH, hypoplastic left heart: DIV, double inlet ventricle; PA/IVS, pulmonary atresia with intact ventricular septum; PA/VSD, pulmonary atresia with ventricular septal defect; Truncus, truncus arteriosus; CTGA, congenitally corrected transposition of the great arteries; CAVSD, complete atrioventricular septal defect; TGA, transposition of the great arteries; PAVSD, partial atrioventricular septal defect; TAPVC, totally anomalous pulmonary venous connection; VSD op/or death, ventricular septal defect with operation or death in infancy; AS op/or death, aortic stenosis with operation or death in infancy; PS op/or death, pulmonary stenosis with operation or death in infancy; ASD, atrial septal defect; PDA, patent ductus arteriosus; VSD, ventricular septal defect with no operation or death in infancy; AS, aortic stenosis with no operation or death in infancy; PS, pulmonary stenosis with no operation or death in infancy. 
Table 2 Year by year birth prevalence of individual cardiovascular malformations using and "anatomical" hierarchy

\begin{tabular}{|c|c|c|c|c|c|c|c|c|c|c|c|c|c|c|}
\hline & 85 & 86 & 87 & 88 & 89 & 90 & 91 & 92 & 93 & 94 & 95 & 96 & 97 & Total \\
\hline HLH & 5 & 5 & 6 & 7 & 6 & 5 & 7 & 5 & 4 & 4 & 6 & 6 & 3 & 69 \\
\hline Mitral atresia & 0 & 0 & 0 & 0 & 3 & 0 & 2 & 1 & 2 & 2 & 2 & 0 & 1 & 13 \\
\hline Tricuspid atresia & 2 & 4 & 2 & 3 & 2 & 2 & 3 & 1 & 2 & 2 & 2 & 0 & 0 & 25 \\
\hline DIV & 3 & 4 & 2 & 4 & 3 & 0 & 5 & 6 & 1 & 2 & 2 & 1 & 0 & 33 \\
\hline PA/IVS & 2 & 2 & 2 & 2 & 2 & 3 & 2 & 2 & 1 & 3 & 2 & 0 & 0 & 23 \\
\hline $\mathrm{PA} / \mathrm{VSD}$ & 1 & 5 & 5 & 4 & 3 & 4 & 3 & 5 & 3 & 6 & 4 & 6 & 2 & 51 \\
\hline Truncus & 4 & 2 & 5 & 9 & 3 & 1 & 2 & 2 & 4 & 3 & 2 & 3 & 4 & 44 \\
\hline CTGA & 1 & 1 & 4 & 2 & 3 & 1 & 2 & 0 & 1 & 2 & 0 & 0 & 2 & 19 \\
\hline CAVSD & 6 & 6 & 7 & 14 & 16 & 11 & 10 & 8 & 16 & 10 & 6 & 10 & 11 & 131 \\
\hline TGA & 15 & 16 & 13 & 5 & 10 & 9 & 10 & 11 & 10 & 14 & 12 & 13 & 7 & 145 \\
\hline ToF & 9 & 7 & 11 & 4 & 12 & 13 & 16 & 13 & 14 & 14 & 12 & 12 & 9 & 146 \\
\hline PAVSD & 3 & 3 & 3 & 4 & 1 & 4 & 2 & 4 & 1 & 4 & 2 & 4 & 3 & 38 \\
\hline TAPVC & 2 & 5 & 3 & 1 & 4 & 5 & 3 & 5 & 4 & 1 & 3 & 6 & 3 & 45 \\
\hline VSD op/or death & 10 & 15 & 23 & 10 & 22 & 18 & 23 & 13 & 35 & 13 & 23 & 14 & 22 & 241 \\
\hline AS op/or death & 5 & 5 & 6 & 2 & 2 & 3 & 2 & 3 & 1 & 7 & 3 & 2 & 5 & 46 \\
\hline PS op/or death & 3 & 3 & 5 & 4 & 12 & 4 & 3 & 6 & 1 & 5 & 1 & 4 & 2 & 53 \\
\hline $\mathrm{CoA}$ & 6 & 7 & 6 & 9 & 8 & 10 & 7 & 8 & 13 & 16 & 11 & 10 & 5 & 116 \\
\hline ASD & 4 & 9 & 7 & 5 & 13 & 5 & 7 & 10 & 9 & 15 & 21 & 11 & 18 & 134 \\
\hline PDA & 4 & 11 & 5 & 14 & 7 & 18 & 13 & 10 & 6 & 7 & 0 & 7 & 7 & 109 \\
\hline VSD & 32 & 35 & 51 & 40 & 50 & 47 & 72 & 77 & 94 & 79 & 102 & 93 & 127 & 899 \\
\hline AS & 0 & 1 & 3 & 7 & 3 & 8 & 5 & 6 & 3 & 2 & 3 & 3 & 3 & 47 \\
\hline PS & 5 & 11 & 9 & 10 & 6 & 8 & 10 & 17 & 8 & 13 & 29 & 12 & 21 & 159 \\
\hline Miscellaneous & 10 & 4 & 4 & 11 & 5 & 6 & 5 & 8 & 9 & 7 & 5 & 8 & 3 & 85 \\
\hline Total & 132 & 161 & 182 & 171 & 196 & 185 & 214 & 221 & 242 & 231 & 253 & 225 & 258 & 2671 \\
\hline
\end{tabular}

See table 1 for abbreviations.

significant that abnormality which requires the earliest intervention or which causes the most haemodynamic disturbance. ${ }^{4}$

In an effort to get round the limitations of each of these two approaches we have adopted a two dimensional classification, defining both the major structural abnormality and, where different, the abnormality precipitating clinical recognition of a cardiovascular malformation. For example, a baby with double inlet left ventricle and coarctation of the aorta would be classified by both these abnormalities, as would a baby with atrioventricular and ventriculoarterial discordance with pulmonary atresia. In both cases the former abnormality would be the more serious or fundamental malformation while the latter would precipitate presentation and diagnosis. All cases of ventricular septal defect, pulmonary stenosis or aortic stenosis were subdivided into those in which death occurred or intervention was required in infancy and those alive without intervention at 12 months. Deaths in these groups were few but in some cases the contribution of the heart defect to the death could not be ascertained retrospectively.

In order to provide larger numbers within each group for more reliable analysis of tempo-

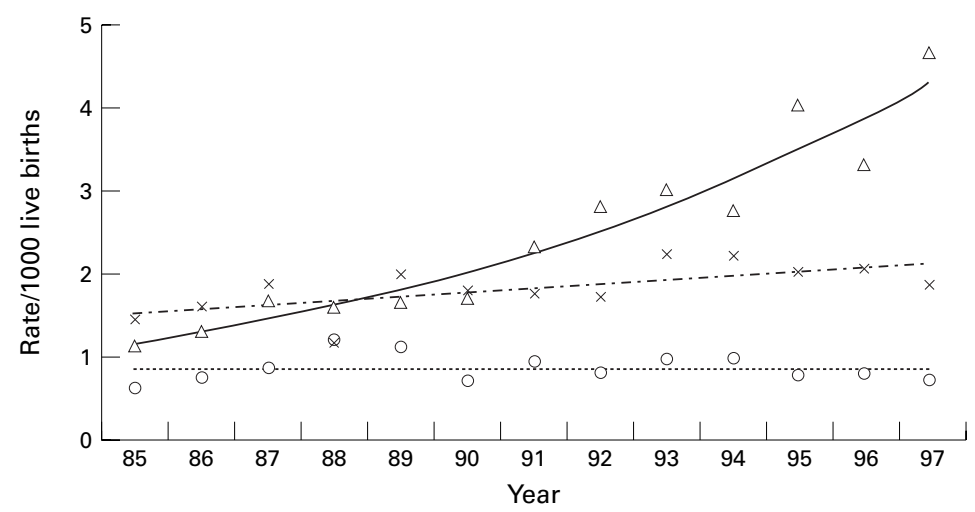

Figure 1 Year by year prevalence at live birth of 411 complex (open circles, dotted line), 870 significant (crosses, dashed line), and 1151 minor (open triangles, solid line) cardiovascular malformations. For definitions see text. ral variability, all cases (with the exception of patent ductus arteriosus and isolated atrial septal defect) were classified as being "complex", "significant", or "minor". ${ }^{16}$ "Complex" heart disease included all cases of heterotaxy or atrial isomerism and all cases characterised by atresia or severe hypoplasia of a valve or chamber. Hearts with a common inlet valve (complete atrioventricular septal defect) or common outlet valve (truncus arteriosus) were also included in this group. Cases of "significant" cardiovascular malformation were those in which four valves and four chambers were present but where intervention was or would be required. This group, for example, includes all cases of simple transposition, tetralogy of Fallot, large ventricular septal defect, coarctation of the aorta, etc. "Minor" malformations were those where intervention would not be required. These were mainly mild or moderate aortic or pulmonary valve stenosis and smaller ventricular septal defects. Rarer malformations included in a miscellaneous group in tables 1 and 2 were also individually classified as complex, significant or minor.

Where there were two or more malformations within the same broad diagnostic group (complex, significant or minor) the hierarchy was as shown by the order of listing in table 1 . For example, a baby undergoing surgical closure of a ventricular septal defect and patent ductus was classified as having a ventricular septal defect, whereas a baby with a small ventricular septal defect requiring ligation of a ductus was classified as having a patent ductus arteriosus. As described above, isolated atrial septal defect and isolated patent ductus arteriosus were analysed separately and were not included in the complex, significant, and minor classification.

Simplified diagnostic hierarchies do not permit detailed subclassification of hearts with straddling atrioventricular valves or relative ventricular hypoplasia, features which will determine the surgical strategy and outcome but which are relatively rare. The diagnostic 
hierarchy does not equate with a classification into those suitable for biventricular or univentricular repair. Our anatomical classification does not include double outlet right ventricle, a diagnostic label which fails to identify an anatomically or physiologically distinct group of heart malformations.

DIAGNOSIS

Cases were included only if they were live born. In all cases the diagnosis was confirmed by echocardiography, cardiac catheterisation, surgery or necropsy. Note was made of the total infant mortality in individual diagnostic categories.

Pregnancies terminated after antenatal diagnosis of congenital heart disease were listed separately.

Any study of cardiovascular malformations in a population would ideally include all affected fetuses and would therefore include complete ascertainment of pregnancies which ended in spontaneous abortion, termination or stillbirth. There is evidence of a high prevalence of cardiovascular malformations in stillbirths but reliable ascertainment is very difficult. ${ }^{17}$ Small changes in fetal survival of some more severe malformations might be
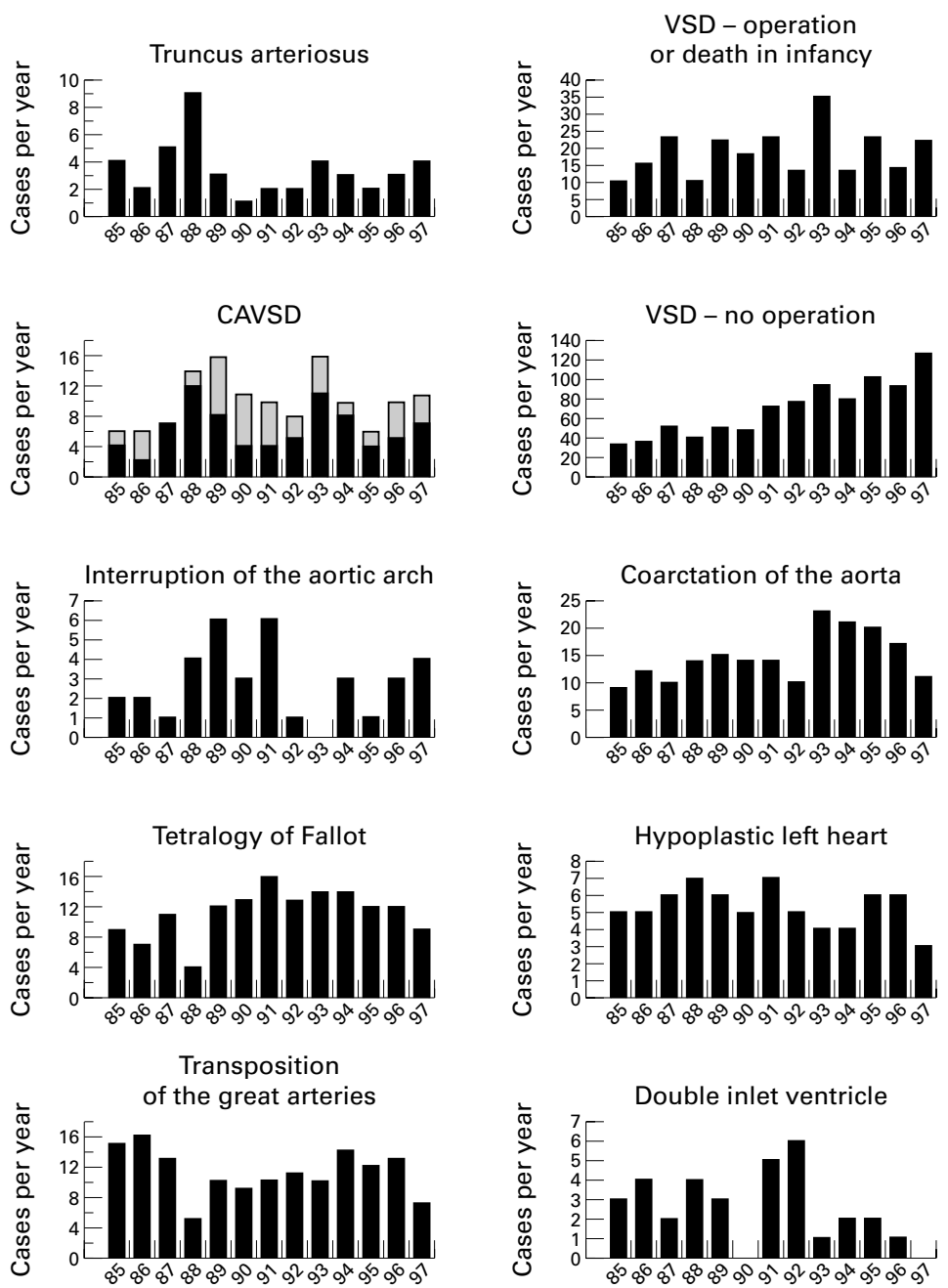

Figure 2 Year by year prevalence at live birth of selected individual diagnoses. VSD, ventricular septal defect; CAVSD, complete atrioventricular septal defect. Data for CAVSD are divided into those with trisomy 21 (black) and without (grey). expected to have a major effect on birth prevalence. ${ }^{18}$ Spontaneous fetal losses were not included in this analysis as there is no rigorous or reliable ascertainment of cardiovascular malformations in these groups in our population.

\section{STATISTICS}

Statistical analysis was limited to analysis of trends over time in the three main diagnostic groups using a Poisson model.

\section{Results}

DENOMINATOR POPULATION

From 1985 to 1997 there were 477960 live births, a mean of 36766 per year. There was a $15 \%$ decline in the birth rate from 38592 in 1991 to 32874 in 1997, exceeding the $9 \%$ fall in births in England and Wales between 1990 and $1997 .^{19}$

BIRTH PREVALENCE

In the 13 years of the study 2671 live born cases of congenital heart disease were identified, a birth prevalence of 5.6 per 1000 . Table 1 shows the prevalence of individual malformations using separate "anatomical" and "physiological" hierarchies. The use of a one dimensional anatomical classification alone would lead to under ascertainment of pulmonary atresia by $28 / 102(27 \%)$ cases, of interruption of the aortic arch by all $36(100 \%)$ cases, and of coarctation of the aorta by $74 / 190(39 \%)$ cases, because they would be classified only according to the most significant intracardiac malformation.

\section{TEMPORAL VARIATION OF LIVE BORN}

CARDIOVASCULAR MALFORMATION

Figure 1 shows the year by year prevalence of congenital heart disease within the three main diagnostic groups. There was a highly significant trend to increase in numbers of minor malformations over time ( $\mathrm{p}<0.0001)$, a slight trend towards increasing numbers of significant malformations which did not reach statistical significance $(p=0.08)$, and no change in complex cases $(\mathrm{p}=0.85)$.

\section{TEMPORAL VARIATION FOR INDIVIDUAL}

MALFORMATIONS

Table 2 shows the year to year variability in the prevalence of individual malformations using the main "anatomical" hierarchy. Figure 2 presents year to year variability for some individual diagnoses. The greatest variation was seen in interruption of the aortic arch, double inlet ventricle, and truncus arteriosus. More variability was apparent in diagnoses with smaller numbers but there was a relatively constant birth prevalence of hypoplastic left heart despite the small numbers. Figure 2 also shows a relatively small variation in the numbers of babies with tetralogy of Fallot or transposition of the great arteries, and a wider variability in the prevalence of complete atrioventricular septal defect. There appears to be a trend towards more cases of coarctation of the aorta, despite complete ascertainment. There is a real increase in the recognition and 


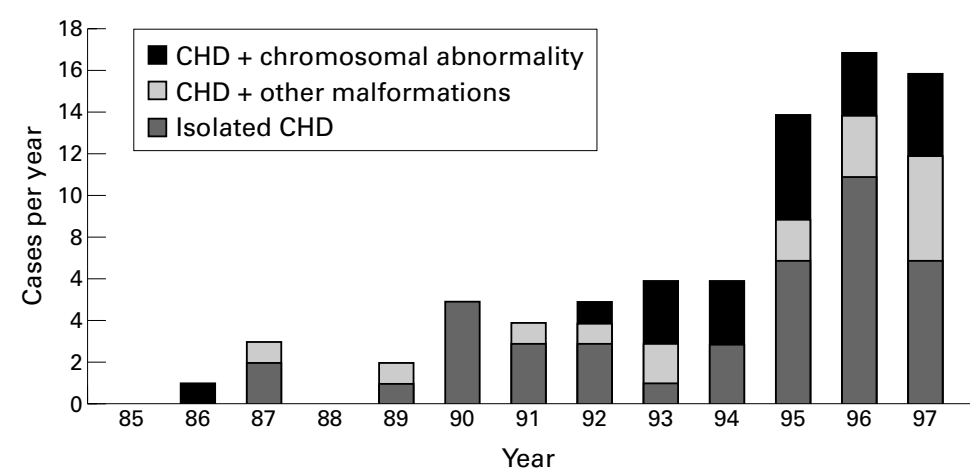

Figure 3 Year by year numbers of terminated pregnancies with congenital heart disease (CHD).

Table 3 Pregnancies with congenital heart disease terminated from 1985 to 1997

\begin{tabular}{llll}
\hline & $\begin{array}{l}\text { CHD }+ \\
\text { chromosomal } \\
\text { abnormality }\end{array}$ & $\begin{array}{l}\text { CHD + other } \\
\text { malformation }\end{array}$ & $\begin{array}{l}\text { Isolated } \\
\text { CHD }\end{array}$ \\
\hline HLH & 0 & 4 & 21 \\
Isomerism & 0 & 0 & 6 \\
CAVSD & 4 & 2 & 4 \\
VSD & 6 & 0 & 0 \\
DIV & 0 & 1 & 4 \\
PA/VSD & 1 & 3 & 0 \\
ToF & 4 & 1 & 0 \\
PAVSD & 2 & 1 & 0 \\
Ectopia cordis & 0 & 2 & 0 \\
AS & 0 & 0 & 2 \\
Mitral atresia & 0 & 0 & 3 \\
Truncus & 1 & 0 & 1 \\
TGA & 1 & 0 & 1 \\
Ebstein/PA & 0 & 0 & 1 \\
Aortic atresia & 0 & 0 & 1 \\
CoA & 0 & 1 & 0 \\
PS & 1 & 0 & 44 \\
Total & 20 & 15 &
\end{tabular}

CHD, congenital heart disease; Isomerism, atrial isomerism; Ebstein/PA, Epbstein's anomaly with pulmonary atresia. See table 1 for other abbreviations.

registration of ventricular septal defects not requiring operation in infancy, but no trend in larger ventricular septal defects requiring surgery or associated with death before the age of 12 months.

\section{ANTENATAL DIAGNOSIS AND TERMINATION OF} PREGNANCY

One possible effect on live born prevalence of congenital heart disease is a policy of termination of pregnancy after antenatal diagnosis. Figure 3 shows the increasing number of terminations during the study period. Of 79 fetuses whose pregnancies were terminated 20 had a cardiovascular malformation associated with a chromosomal abnormality, 15 with other major malformation, and 44 had isolated heart disease. Confirmed post mortem diagnoses are shown in table 3.

\section{Discussion}

Examination of published reports on the birth prevalence of congenital cardiovascular malformations emphasises the need for a constant method in order to be able to examine apparent differences. $^{5}{ }^{20}$ There have been many reports but few meet the criteria of being population based, including only confirmed diagnoses, and limiting ascertainment to the first 12 months of life. There is also wide variation in the diagnostic hierarchies employed. ${ }^{414} 1521$
The differences in the birth prevalence of cardiovascular malformations in different populations might be a clue to a genetic or environmental cause, but the reported variation in prevalence is almost certainly accounted for by variation in ascertainment. ${ }^{50}$ Even in large studies there are small numbers of the less common diagnoses and so no conclusions can be drawn from differences reported in the birth prevalence of rarer malformations.

This study is one of the largest to date with a denominator of nearly half a million live births. We think we have full ascertainment of "complex" and "significant" cardiovascular malformations, but there is inevitably some under ascertainment of minor malformations from the early years (1985 to 1989).

Diagnostic registers have a problem in classifying babies with multiple cardiovascular malformations. Institution based studies tend to deal with the abnormality which precipitates presentation or referral ${ }^{410}$ whereas population based studies usually rank abnormalities according to anatomical severity. ${ }^{14}{ }^{15}$ Many older studies give no indication of how multiple malformations were dealt with. Other "embryological" hierarchies have been proposed but have not gained acceptance. ${ }^{21}$ The diagnostic hierarchy presented here offers a standard and highlights the diagnoses likely to be under or over represented in studies using either anatomical or physiological hierarchies - that is, pulmonary atresia, interruption of the aortic arch, coarctation of the aorta, and total anomalous pulmonary venous connection.

This study also shows significant time related variation in the birth prevalence of cardiovascular malformations. The main reasons are better ascertainment with prospective registration, difficult retrospective ascertainment of minor malformations from the early years of the study, and increasing recognition of minor malformations using colour Doppler echocardiography, mainly of small ventricular septal defects. ${ }^{7}$ Several previous studies have documented an increase over time in the identification of more minor cardiac malformations and have attributed the change to better ascertainment. ${ }^{7822-24}$ Year to year variation in the numbers of live born babies with less common malformations is quite striking (fig 2), but is almost certainly accounted for in the random variation of small numbers.

The increase in antenatal diagnosis of severe cardiovascular malformations and termination of affected pregnancies would be expected to lead to fewer cases being live born. So far it has been difficult to demonstrate this in any population based study. ${ }^{65}$ The termination of pregnancy after antenatal diagnosis of cardiovascular malformation is increasing in our catchment area, as in other regions, ${ }^{6}{ }^{26}$ but we could show no effect of this on the prevalence at live birth of congenital heart disease. The natural history of heart disease diagnosed in utero is not clear and is obviously affected by termination of pregnancy. However, we cannot assume that those fetuses whose pregnancies were terminated would all have been live born. Fetal mortality varies considerably between 
diagnoses ${ }^{27}$ and there is a well recognised excess of cardiovascular malformations in stillbirths. ${ }^{17}{ }^{18}$ In the long run the increase in antenatal diagnosis and termination of pregnancy is likely to lead to fewer live born babies with cardiovascular malformations, but so far any effect is masked by the variation in small numbers and the decline in birth rate. Pregnancies terminated will tend to be those of fetuses with the most severe, and therefore most easily recognised, malformations and with the poorest prospect of natural survival.

Within a given population there are likely to be several influences on the birth prevalence of congenital heart disease. Better ascertainment, better non-invasive diagnosis, and survival into adult life with a higher risk to offspring are likely to increase the number of diagnoses, whereas antenatal diagnosis and termination of pregnancy will reduce the prevalence at live birth of the more severe forms of heart disease. Unknown environmental influences could have either effect. The prevalence of heart defects will also obviously be influenced by the overall birth rate. When individual diagnoses are considered, year to year variations in small numbers are likely to be large making it difficult to prove that any change results from any specific intervention.

We are indebted to Professor John N S Matthews of the department of statistics, University of Newcastle for statistical analysis, to Kati Whiteoak for data collection and compilation, and to the Children's Heart Unit Fund for financial support of the paediatric cardiology database.

1 Abu-Harb M, Hey E, Wren C. Death in infancy from unrecognised heart disease. Arch Dis Child 1994;71:3-7.

2 Hoffman JI. Incidence of congenital heart disease: I. Postnatal incidence. Pediatr Cardiol 1995;16:103-13.

3 Hoffman JI. Congenital heart disease: incidence and inheritance. Pediatr Clin North Am 1990;37:25-43.

4 Moller JH, Moodie DS, Blees M, et al. Symptomatic heart disease in infants: comparison of three studies performed during 1969-1987. Pediatr Cardiol 1995;16:216-22.

5 Ferencz C, Czeizel A, Lys F. The problem of comparative analysis of birth prevalence of congenital cardiovascular malformations. Acta Paediatr Hung 1990;30:169-89.

6 Bull C. Current and potential impact of fetal diagnosis on prevalence and spectrum of serious congenital hear disease at term in the UK. Lancet 1999;354:1242-7.
7 Lewis DA, Loffredo CA, Correa-Villasenor A, et al. Descriptive epidemiology of membranous and muscular
ventricular septal defects in the Baltimore-Washington ventricular septal defects in the Baltimore
infant study. Cardiol Young 1996;6:281-90.

8 Tikanoja T. Effect of technical development on the apparent ncidence of congenital heart disease. Pediatr Cardiol 1995; 16:100-1.

9 Hoffman JIE. Reflections on the past, present and future of pediatric cardiology. Cardiol Young 1994;4:208-23.

10 Wren C, Richmond S, Donaldson L. Presentation of congenital heart disease in infancy: implications for provision of service. Arch Dis Child Fetal Neonatal Ed 1999;80:F49-53.

11 Northern Regional Survey Steering Group. Fetal abnormalty, an audit of its recognition and management. Arch Dis Child Fetal Neonatal Ed 1992;67:F770-4.

12 Northern Regional Health Authority Coordinating Group. Perinatal mortality: continuing collaborative regional group. BMF 1984;288:1717-20.

13 Mitchell SC, Korones SB, Berendes HW. Congenital heart disease in 56,109 births. Circulation 1971;43:323-32.

14 Fyler DC. Report of the New England regional infant cardiac program. Pediatrics 1980;65(suppl):377-461.

15 Ferencz C, Rubin JD, McCarter RJ, et al. Congenital heart disease: prevalence at live birth. The BaltimoreWashington infant study. Am F Epidemiol 1985;121:31-6.

16 Abu-Harb M, Wyllie J, Hey E, et al. Antenatal diagnosis of congenital heart disease and Down's syndrome: the potential effect on the practice of paediatric cardiology. Br Heart 7 1995;74:192-8.

17 Chinn A, Fitzsimmons J, Shepard TH, et al. Congenital heart disease among spontaneous abortuses and stillborn fetuses: prevalence and associations. Teratology 1989;40: $475-82$

18 Hoffman JI. Incidence of congenital heart disease: II. Prenatal incidence. Pediatr Cardiol 1995;16:155-65.

19 Office for National Statistics. Mortality statistics: childhood, infant and perinatal. Series DH3 no 30. London: The Stationery Office, 1997.

20 Ferencz C. On the birth prevalence of congenital heart disease. F Am Coll Cardiol 1990;16:1701-2.

21 Jackson M, Walsh KP, Peart I, et al. Epidemiology of congenital heart disease in Merseyside-1979 to 1988. Cardiol Young 1996;6:272-80.

22 Fixler DE, Pastor P, Chamberlin M, et al. Trends in congenital heart disease in Dallas County births 19711984. Circulation 1990;81:137-42.

23 Mayberry JC, Scott WA, Goldberg SJ. Increased birth prevalence of cardiac defects in Yuma, Arizona. 7 Am Coll Cardiol 1990;16:1696-700.

24 Roy DL, McIntyre L, Human DG, et al. Trends in the prevalence of congenital heart disease: comprehensive observations over a 24-year period in a defined region of Canada. Can 7 Cardiol 1994;10:821-6.

25 Montana E, Khoury MJ, Cragan JD, et al. Trends and outcomes after prenatal diagnosis of congenital cardiac malformations by fetal echocardiography in a well defined birth population, Atlanta, Georgia, 1990-1994. F Am Coll Cardiol 1996;28:1805-9.

26 Wyllie J, Wren C, Hunter S. Screening for fetal cardiac malformations. Br Heart f 1994;71:20-7.

27 Allan LD, Sharland GK, Milburn A, et al. Prospective diagnosis of 1006 consecutive cases of congenital heart disease in the fetus. F Am Coll Cardiol 1994;23:1452-8. 